\title{
THE VALUATION OF BONDS ON AN INCOME BASIS
}

\author{
By Charles E. Sprague, Ph.D., New York, \\ President, Union Dime Savings Institution, and Author of "Extended Bond \\ Tables." \\ Effect of premium or discount upon income basis-Nominal and effectiv \\ rates of interest-Arrangement of tables-Experimental test of correct- \\ ness-Valuation by discounting-Use of logarithms-Formula for values- \\ Extent and closeness of tabular values-Intermediate times-"Flat"; "and \\ interest"-Intermediate incomes-Correction of approximates-The "I/8 \\ rule"-Intermediate nominal rates-Quarterly bonds-Annual bonds- \\ Optional date of redemption-Redemption above or below par-Serial \\ bonds-Finding the basis-The sinking fund theory.
}

If a bond for $\$ \mathrm{I}, 000$ is purchased at par and the interest is $\$ 50$ per annum, it is evident that the income-basis to the investor is 5 per cent exactly, irrespectiv ${ }^{1}$ of when the bond matures. If, however, the price is in the slightest degree greater than par, the interest on the capital invested is at a less rate than 5 per cent. For example, if the price paid is $\$ \mathrm{I}, 250$, the income-basis cannot be more than 4 per cent, for $\$ 50$ is only 4 per cent of the capital invested. But this is not all; besides the reduction of rate produced by increase of principal, there is another cause at work: the $\$ 250$ premium will have vanisht by the date of maturity, for the obligor will only pay the $\$ 1,000$. The $\$ 250$ must be repaid from the interest, reducing the rate, or income basis, still more.

In the same way it may be shown that if less than par were invested, the income-basis, or effectiv rate, would be greater than the nominal or cash rate, for two reasons: first, because the principal is less, and therefore $\$ 50$ is a higher percentage of it; second, because of the increment which will be realized as the bond rises to par at maturity.

Thus there may be two different rates of interest on a bond, the nominal rate and the effectiv rate: or the cash rate and the income-basis. When the bond is at a premium, the cash rate is the higher; when the bond is below par, the cash rate is lower.

'The abbrevlated spelling is followed in this paper at the special request of the author.-Thw EDITor.

(20I) 
The cash-rate is based on par, the income-basis on the amount of the investment at the time being.

Computations have been made of the price at which a bond should be bought to yield at a certain income-basis, the following facts being known: the nominal rate per annum, and how frequently payable; the effectiv rate of income-basis required; and the length of time the bond has to run. These results are publisht in tables which are usually founded on half-yearly payments of interest, that being the prevalent custom. They present the values either to the nearest cent on one hundred dollars or to the nearest cent on one million dollars, the latter serving for more exact calculations than the former and on greater amounts of principal.

Before treating of the method of computing these tables we will take a result as given by them and test the assertion that it does actually yield a certain income-basis.

A bond for $\$ 1,000,000,5$ per cent cash interest, payable semiannually, one and a half years to run, income basis 4 per cent. We turn to the tables and find from the smaller tables that the value of $\$$ Ioo would be $\$$ ror.44. The more extended tables give the value of $\$ 1,000,000$ as $\$ 1,014,419.42$. We have now to see whether the investor who pays that price does actually receive 4 per cent on his investment.

The successiv values as given by the tables are:

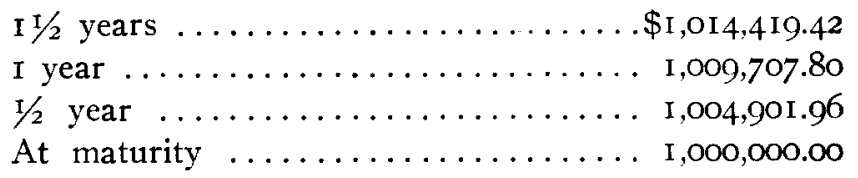

These values are all susceptible of the same proof.

Commencing with $\ldots \ldots \ldots \ldots \ldots \ldots \ldots \ldots \ldots$ I, 0I 4,4 I 9.42

the interest for 6 months at 4 per cent on the sum is. . $\$ \mathbf{2 0 , 2 8 8 . 3 9}$ But the value of the coupon is $\ldots \ldots \ldots \ldots \ldots \ldots \ldots, 25,000.00$

and there is an excess of $\ldots \ldots \ldots \ldots \ldots \ldots \ldots \ldots$ \$4,7 II.6I This is not income at all, but a repayment of part of

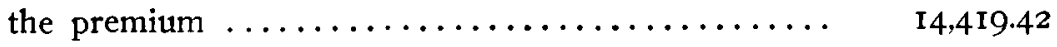

which is now reduced to $\$ 9,707.8 \mathrm{r}$ 
This agrees with the result from the table except one cent, the result of neglected fractions of a cent.

Taking the value $\ldots \ldots \ldots \ldots \ldots \ldots \ldots \ldots \ldots \ldots \ldots \ldots, 0 \ldots 9,707.8 \mathrm{I}$

2 per cent interest of which is $\ldots \ldots \ldots \ldots \ldots \ldots \ldots, \$ 20,194.16$ we subtract this from $\ldots \ldots \ldots \ldots \ldots \ldots \ldots \ldots \ldots, 25,000.00$

and have an excess of $\ldots \ldots \ldots \ldots \ldots \ldots \ldots \ldots . \$ \ldots 4,805.84$ which reduces the value of the bond to ......... 1,004,901.97

which again agrees with the table within a cent.

Repeating the process .................\$20,098.04 from $\ldots \ldots \ldots \ldots \ldots \ldots \ldots \ldots \ldots \ldots \ldots .25,000.00$

$\$ 4,901.96$

This completely exhausts the premium by the process known as Amortization.

Had the original figures been extended to mills instead of cents the discrepancy of one cent would have disappeared.

$\mathrm{Had}$ the figures been taken from the shorter table, substantially the same result would have been attained.

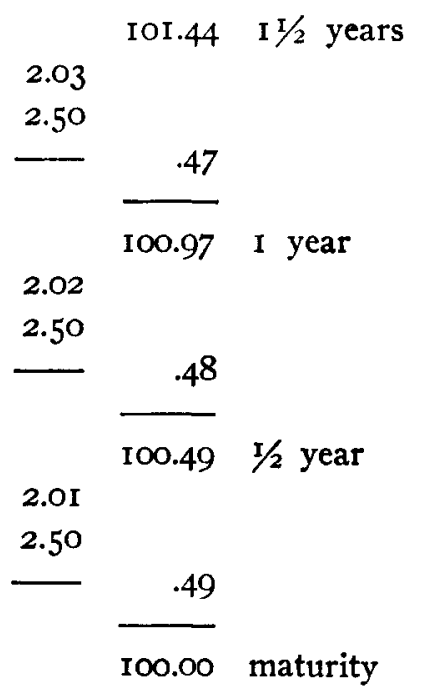

Any value given in any of the tables may be tested by this (203) 
process; taking the value for one half-year earlier and then amortizing down.

Thus the cash-interest is a constant percentage of par, while the income is a constant percentage of the diminishing principal actually remaining invested; such diminution or amortization being effected by using the excess of cash-interest over effectiv income.

Exactly the opposit course is taken in case of a bond below par; the difference between the nominal and the effectiv interest adds to the value and by accumulation brings it to par at maturity.

These tables might have been computed (with considerable labor) by simple arithmetic. It is only necessary to discount the total to be received, including the coupon.

Thus, the 5 per cent bond already mentioned calls for the payment

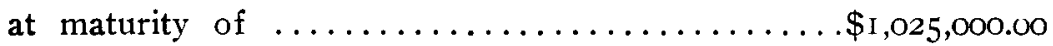
Dividing this by 1.02 , we have as the value six months

earlier ........................ Adding $\ldots \ldots \ldots \ldots \ldots \ldots \ldots \ldots \ldots \ldots \ldots \ldots \ldots, \quad 25,000.00$

$\$ 1,029,901.96$ and, again dividing by 1.02 , we get $\ldots \ldots \ldots \ldots \ldots$ r,009,707.80 Again adding $\ldots \ldots \ldots \ldots \ldots \ldots \ldots \ldots \ldots \ldots, \quad 25,000.00$

$\$ 1,034,707.80$

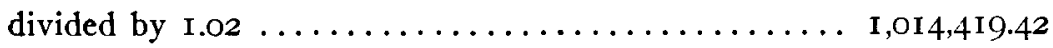

These results again agree with those given in the tables. This discounting-method might be practically used for a few periods if the income rate is a very complicated one, not found in the tables, but it would be very tedious if continued for, say, Ioo periods or fifty years.

By the use of logarithms a value for a large number of periods may be found almost as quickly as for a small number. Only one of the necessary factors requires the use of logarithms; the rest of the operation is easier by simple multiplication and division.

We will give the algebraic formula for obtaining the premium or discount, using the following notations: $i$ the rate of interest per (204) 
period exprest decimally; $n$, the number of periods; $c$, the cash income of $\$ \mathrm{I}$, or nominal rate. Then the value of a $\$ \mathrm{I}$ bond is

$$
\mathrm{I}+\frac{c-i}{i} \times\left(\mathrm{I}-\frac{\mathrm{I}}{(\mathrm{I}+i)^{\mathrm{n}}}\right)
$$

If $c>i$, the result will be greater than unity; if $c>\imath$, the result will be less than unity.

The only quantity which necessitates the use of logarithms is $\frac{r}{(r+i)^{n}}$ or, as it might be written $(x+i)-n$. This is the present worth of $\$$ I payable $n$ periods hence at the rate $i$. When this has been accurately obtained, the rest is easy. This present worth might also be found from tables of compound interest.

The bond-tables vary as to their range of time, of cash rate, of income basis. As to time, they usually give each half-year up to 50 years, sometimes extended to. Ioo by jumps of 5 years or $2 \mathrm{I} / 2$ years. As to nominal, or cash rate, they usually comprise the following rates, or the most of them: 2 per cent bonds, $2 \frac{1}{2}, 3,3 \frac{1}{2}$, $3.65,4,4 \frac{1}{2}, 5,6,7$. They do not usually cover the odd rates which sometimes occur, such as $3.60,3.75$, or 3.80 per cent bonds. These are easily derived. As to income-basis, some of them advance by eighths, thus, $3,3 \frac{1}{1} / 8,3 \frac{1}{4}, 3 \frac{3}{8}, 3 \frac{1}{2}, 3 \frac{5}{8}, 33 \frac{1}{4}, 37 / 8,4$ per cent basis, etc. Other tables advance by tenths of I per cent, like 3, 3.10, 3.20, 3.30, 3.40, etc. Others still advance by twentieths, 3, 3.05, 3.10, $3.15,3.20,3.25$, etc., and this is the closest regular advance given by any tables yet publisht. In all of these particulars, intermediates may be interpolated; intermediate times, intermediate cash-rates, intermediate bases of interest. The means of interpolation will now be explained.

The above examples refer to entire periods, not to times comprising odd months or days. When the time falls in the midst of a term or period, there are two ways of stating the price: "flat," or "and interest." The former includes the interest which, at cashrate, has accrued since the last interest-day; the latter excludes this accrued interest.

If in the example above the time were one year and three months instead of one year and six months, the price would be $\ldots \ldots \ldots \ldots \ldots \ldots \ldots \$ 1,024,563.61$ flat 
or $\ldots \ldots \ldots \ldots \ldots \ldots \ldots \ldots \ldots \ldots \ldots \ldots \ldots \ldots \ldots, 1,012,063.61$ and interest As the accrued interest for 3 months at 5

per cent is ................ $12,500.00$

it is evident that these two express the same values.

The flat price may be found by multiplication and the price ex-interest by proportion.

If we take the value $\ldots \ldots \ldots \ldots \ldots \ldots \ldots \ldots \ldots \$$ I ,or $4,419.42$ and to it add interest thereon for 3 months at 4

per cent $\ldots \ldots \ldots \ldots \ldots \ldots \ldots \ldots \ldots \ldots \ldots \ldots$ Io,r 14.19

we have the flat price $\ldots \ldots \ldots \ldots \ldots \ldots \ldots \ldots . \$ 1,024,563.6 \mathrm{I}$

If we take a value halfway between.........\$1,014,419.42 and the one-year value $\ldots \ldots \ldots \ldots \ldots \ldots \ldots \ldots \ldots, 1,009,707.80$

We have the and-interest price $\ldots \ldots \ldots \ldots \ldots \ldots \$ 1,012,063.6 \mathrm{I}$

The latter method is generally considered the simpler. It consists in proportioning the amortization for the period to the time elapsed: $1 / 18$ of the six months amortization being supposed to "run off" each day. The "360-day" rule is now the only one used for accrued interest, having been adopted by the leading brokers in New York a few years ago.

It may be remarkt that this rule for intermediate dates rests upon custom and convenience, but is not absolutely correct, nor equitable as between buyer and seller. The buyer advances the accrued interest, which is like a non-interest-bearing loan to the seller for the remainder of the term. The buyer might claim, and perhaps legally, that the price is the present worth for the unfinisht time, obtained by discount. For times less than six months this is frequently done. Thus, a three-months' value of the same bond by the ordinary brokers' rule would be

By discount, it would be $\$ 1,025,000 \div$

$$
\begin{aligned}
& \$ 1,002,450.98 \text { and interest } \\
& \text { or } 1,014,950.98 \text { flat }
\end{aligned}
$$

r.or, or ................

a difference of $\ldots \ldots \ldots \ldots \ldots \ldots \ldots . \quad 99.49$

The buyer would support his claim by the following calculation : 
If I invest $. \$ 1,014,851.49$

I am entitled to $\mathrm{I}$ per cent on my money for the quarter, as our contract calls for a yield to me at 4 per cent per annum ; I per cent is ............. I0, I48.5 I and $I$ receive exactly the amount $\ldots \ldots \ldots \ldots \ldots \ldots \overline{\$ I, 025,000.00}$

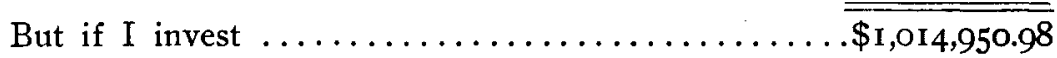
Interest on that is $\ldots \ldots \ldots \ldots \ldots \ldots \ldots \ldots \ldots$ ro, I49.5I

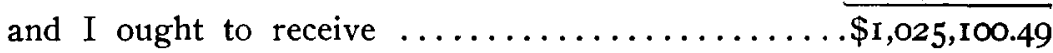
What $I$ do receive is only $\ldots \ldots \ldots \ldots \ldots \ldots \ldots \ldots, \mathrm{I}, 025,000.00$

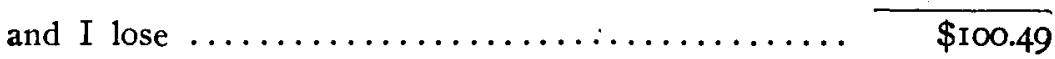

Neither of these methods gives to both buyer and seller the same rate of income. The exact value for that purpose would be $\$$ I,OI4,9OI.23, about halfway between the two results by multiplication and division; and this would yield to each a rate equivalent to 2 per cent per half year; not I per cent, but .995049 per cent.

A basis of income intermediate to those given in the table may often be required. For example, if the table gives the values at 2.50 and at 2.60 , it may be desired to find the value at 2.54 or 2.55 or 2.56. The midway rate, 2.55 , is more frequently needed than any other. Both in the shorter and the more extended tables these intermediates are first found approximately by simple proportion. A 7 per cent bond for 50 years at a 2.50 per cent basis

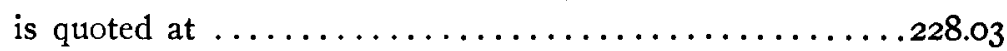

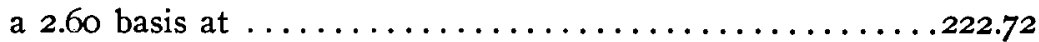

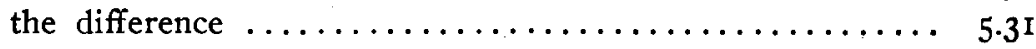

represents ro points;

5 points would be $\ldots \ldots \ldots \ldots \ldots \ldots \ldots \ldots \ldots \ldots \ldots \ldots, 2.655$

therefore the value for a 2.55 basis would be.........225.375 approximately.

To correct this; we must set down three successiv values; and in two columns alongside, their differences and the difference of these differences, called a "second difference."

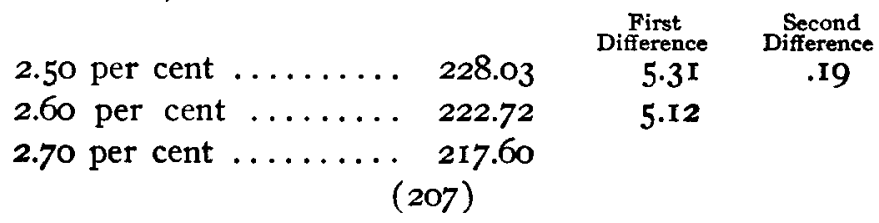


The correction always consists in subtracting one-eighth of the second difference from the approximate value.

Approximate value ............. 225.375

One-eighth of .19 $\ldots \ldots \ldots \ldots \ldots \ldots \ldots . .024$

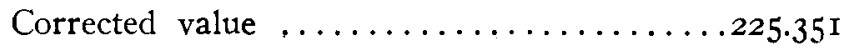

This value would in practice be "rounded off" to 225.35 . The actual value extended to 6 decimals is 225.35 I 754 .

This correction need only be applied to high values; for less than 23 years there can be no second difference large enough to affect the result. The extended tables have, or should have, auxiliary tables for correcting the approximate values exactly or within a cent or two, and this may be done without even the trouble of the differencing process. The " $\mathrm{I} / \mathrm{s}$ " rule for correcting the short tables was devised by the writer and has not, so far as he knows, appeared before in print.

We have now explained the method of interpolating odd times and odd bases, in each of which a fair approximation is obtained by merely dividing the interval into equal parts. When we come to the cash rate, no correction is needed; the 5 per cent bond on any income basis is exactly midway between the 4 per cent and the 6 per cent. Any bond at an odd rate may be derived from the values of the next regular rates above and below. Thus, on a 2.50 basis for 25 years, the value of a $4^{1} / 3$ per cent bond might be found thus :

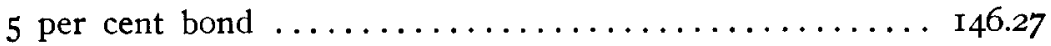

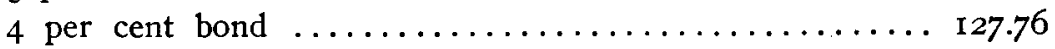

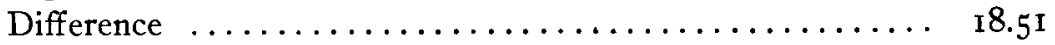

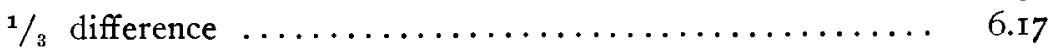

which, added to the 4 per cent, gives $\ldots \ldots \ldots \ldots \ldots \ldots \ldots$ I 33.93 as the value of a $4 \frac{1}{3}$ per cent bond, if such a bond were issued.

Some bonds provide for paying interest every quarter instead of every half-year. If we take two bonds, both nominally 5 per cent per annum, the one quarterly and the other semi-annually; the former, on the same income-basis, is worth a higher premium. Let us suppose that each is on a 4 per cent semi-annual basis; it 
will not do to have one basis quarterly and the other semi-annual, for these would not be the same. The bond being supposed to be one for $\$ 1,000$,

the quarterly coupon is $\ldots \ldots \ldots \ldots \ldots \ldots \ldots \ldots \ldots \ldots 12.50$

The holder of the coupon has the use of this during the other

quarter, and this is worth, at 4 per cent $\ldots \ldots \ldots \ldots \ldots$.r2

At the end of the half-year there is another coupon....... 12.50

so that this bond pays $\ldots \ldots \ldots \ldots \ldots \ldots \ldots \ldots \ldots \ldots \ldots \ldots 25.12$

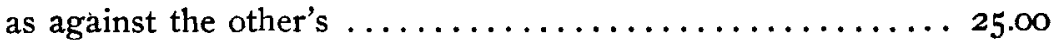

that is 5.025 per cent instead of 5 per cent. As .025 equals $1 / 40$, we must add to the value at 5 per cent $1 / 40$ of the difference between the 5 per cent and the 6 per cent values.

Let us try this on a Io-year value. We find opposit the 4 per cent basis

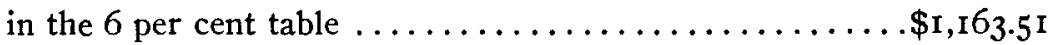

in the 5 per cent table $\ldots \ldots \ldots \ldots \ldots \ldots \ldots \ldots \ldots$ I,081.76

Difference $\ldots \ldots \ldots \ldots \ldots \ldots \ldots \ldots \ldots \ldots \ldots \ldots \ldots \ldots \ldots$

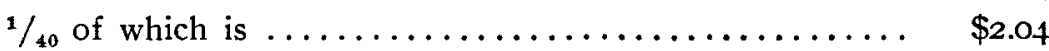

and this added to $\ldots \ldots \ldots \ldots \ldots \ldots \ldots \ldots \ldots \ldots \ldots, \mathbf{1}, 081.76$

gives the value of the quarterly bond $\ldots \ldots \ldots \ldots \ldots \ldots \$ 1,083.80$

on a basis of 4 per cent semi-annual.

The mistake is often made of giving the basis as well as the cash rate quarterly; for example, expecting the bond whose nominal rate is 5 per cent quarterly to yield an income-basis of 4 per cent, also quarterly. To yield that basis it would be worth only $\$ \mathrm{r}, 082.09$. But this would be of no value for purposes of comparison with the half-yearly bond; the basis must be identical in all respects. Annual bonds are less valuable on a given income-basis than semi-annual, and the reasoning is much the same.

Both for quarterly and for annual bonds, some bond-tables give multipliers for finding how much should be added or subtracted to compensate for the change in time of interest payment.

Some honds have a double date of maturity, they are positivly payable at a certain date, but redeemable at an earlier date, at the 
option of the borrower. What date is then to be taken as the date of maturity?

In all such cases the investor should, in order to be safe, not reckon upon the alternativ which is in his favor, but on the one which is adverse. His interests and those of the borrower are naturally antagonistic, and the option will be exercised in favor of the one holding it.

Consequently, the investor who pays a premium must expect the bond to be called in at the earlier date, but he who buys at a discount must expect to hold to maturity. If it does not turn out that way, there is an incidental gain, due to one of two causes: either the general rate of interest has lowered or the security for this particular loan has increast, bringing it into a higher grade, that is to say, lower interest. In the former case, the investor's good fortune is offset by the less favorable chance for re-investment; in the latter case, he has a real profit.

Sometimes the option of redemption exists, but not at par. A bond may be absolutely payable in 50 years, but redeemable after 25 years at 105. The principle of expecting the worse alternativ is here applied in a different manner. First, assuming the longer period to rule, ascertain whether, at the redemption date, the amortization will have brought the bond below 105 or not. If the price on the same income basis will be below 105 at the redemption date, then the redemption should be assumed to fail of accomplishment and the bond will run for the full fifty years. But if the sum invested is so much greater that amortization will not bring it below I05 at the twenty-fifth year, then the bond is a 25-year bond for I05, not a 50-year one for 100 .

Bonds are often issued in serial form. They do not come due all at one time, but so many each year; for example, an issue of $\$ 10,000$ payable $\$ I, 000$ in Io years, $\$ 1,000$ in II years, $\$ I, 000$ in I2 years, and so on, the last being payable ig years from the date of issue. A very common but erroneous manner of valuing such a series is to consider it all payable at the "average date," which would be $141 / 2$ years, the arithmetical mean between Io and 19. By adding together the values at some given income-basis it will be seen that this is incorrect; it is unjust to the buyer if above par, and unjust to the seller if below par. The only correct way is to 
take from the tables the values for the respectiv time each bond has to run and add all these together; what is known among brokers as "separate maturities."

The question, so far, has been: what is the value at a certain basis? The converse question, What is the basis of a certain value? cannot be solved by any direct mathematical process, but the actuarial writers give approximate formulas which are rather complicated. The writer has discovered a simple method of gradual approximation which is now publisht for the first time.

Let us give the name of trial-divisor to the difference between the values of a 4 per cent and a 5 per cent bond on the same basis and for the same time; or, what is the same thing, between a 5 per cent and a 6 per cent, or a 3 per cent and a 4 per cent; always I per cent difference in the nominal rates.

Assume arbitrarily for trial any income rate; the nearer to the true rate as indicated by the tables the less the work of approximation. Find the trial-divisor at this trial rate. Divide the given premium (or discount) by this trial-divisor. The quotient is to be subtracted from the nominal rate if the bond is above par, or added to it if below par; the result will be an approximate rate which will be nearer the truth than the trial rate, being too great when the trial rate is too small and vice versa. This approximate may be used as a new trial rate and will result in a still closer approximation.

For example, take a 4 per cent bond, twenty-five years to run, selling at I 14.00 what is the basis?

Nominal rate 4 , premium 14 , let 3 per cent be the assumed rate. By any tables a 4 per cent bond at a 3 per cent basis

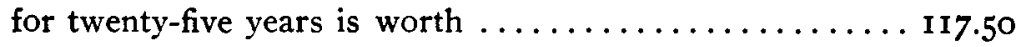
and a 5 per cent bond is worth $\ldots \ldots \ldots \ldots \ldots \ldots \ldots \ldots+135.00$ The trial-divisor is therefore $\ldots \ldots \ldots \ldots \ldots \ldots \ldots \ldots$ I7.50 $14 \div 17.50=.80 ; 4-.80=3.20$. 3.20 is therefore a nearer approximation than 3 per cent.

We now assume 3.20 as a trial rate. Trial-divisor for 3.20 . I30.8I- I I3.70 = I7.1 I. $\quad$ I $4 \div$ I7.II $=.818 . \quad 4-.818=3.182$.

We now assume 3.18 as a trial rate. 17.31 being the trialdivisor for 3.10 and I7.II that for 3.20, it follows that 17.15 is the trial-divisor for 3.18 . $14 \div 17.15=.816 .4-.816=3.184$. As 
3.182 is too small and 3.184 is too great, it is safe to take the rate as between the two and nearer to 3.I84. Without the use of more extended tables, it is safe to say that the basis is 3.18 to. the second decimal.

Had more extended tables been used, with auxiliary differences, this mode of approximation would have been unnecessary, altho it might have been applied. The value at 3.18 would be given directly as II4.0125+, and by arithmetical interpolation the rate required would appear as 3.18367 .

The re-investment of the instalments of amortization has nothing to do with the fact that a certain effectiv rate of interest has been earned by the capital so long as it was invested in this form. The re-investment is a new operation dealing with the future, and does not affect the past. The few writers who asume that the whole theory of amortization depends upon the creation of a sinking-fund to be utilized at maturity but not before, and who have made present values depend on an arbitrary rate of 4 per cent in the accumulation of this sinking-fund, hold opinions contrary to those of the most eminent actuarial writers.

It might as well be claimed that a serial issue of 5 per cent bonds at par, payable $\$ 1,000$ each year, did not pay 5 per cent because you could not re-invest each $\$ 1,000$ so as to pay 5 per cent up to the last maturity. A bond at a prenium is practically a serial bond, the successiv repayments not being uniform like this $\$ 1,000$ series, and the last being much larger than any of the preceding ones. 